\title{
Aluminium Morphological Modification by Nitrogen-Argon Mixture PIII
}

\author{
A.E. Muñoz-Castro ${ }^{a}$, R. López-Callejas ${ }^{a, b, *}$, R. Valencia Alvarado ${ }^{a}$, \\ R. Peña-Eguiluz ${ }^{a}$, A. Mercado-Cabrera ${ }^{a}$, S.R. Barocio ${ }^{a}$, \\ B.G. Rodríguez-MÉndez ${ }^{a}$ And A. DE la Piedad-Beneitez ${ }^{b}$ \\ ${ }^{a}$ Instituto Nacional de Investigaciones Nucleares, AP 18-1027, 11801, Mexico DF \\ ${ }^{b}$ Instituto Tecnológico de Toluca, AP 890, Toluca, Estado de México, Mexico
}

With incident fluences of $\approx 10^{12}$ atoms $/ \mathrm{cm}^{2}$ aluminium samples have been plasma immersion ion implanted with either pure nitrogen or argon/nitrogen mixtures at temperatures around $450{ }^{\circ} \mathrm{C}$. X-ray diffraction studies have validated the formation of the cubic phase of AlN, in samples treated with both the gas mixtures and pure nitrogen. Likewise, the presence of the hexagonal phase of AlN has been detected when either pure nitrogen or a $70 \% \mathrm{~N} / 30 \% \mathrm{Ar}$ mixture have been used. The signature peak of AlN has also been confirmed by the Raman spectroscopy. The maximal microhardness values were found in samples treated with the mixture. The maximal roughness was achieved with the equal part mixture in all cases, although increasing with the implantation pulse width up to a $300 \mathrm{~nm}$ peak at $150 \mu \mathrm{s}$. The latter critical value remains invariant under the pure nitrogen plasma treatment, provided that implantation periods in the order of $4.5 \mathrm{~h}$ are carried out.

PACS: 52.40.Hf, 52.77.Dq, 81.65.-b, 61.05.cp, 62.20.Qp, 68.37.Hk

\section{Introduction}

Aluminium and its alloys are fundamental in industries such as construction, chemical, aero-spatial, car, etc. due to its attractive low weight/high strength ratio. However, further industrial applications demand an increased surface hardness and wear resistance, whereby surface modification becomes indispensable. Nitriding is an effective surface modification process used to enhance corrosion resistance in addition to improving wear resistance. The formation of aluminium nitride (AlN) during nitrogen ion implantation on aluminium has been investigated [1-3].

It is well known that the formation of an AlN layer also improves the corrosion resistance with treated specimens corroding slower than untreated specimens and showing no pitting corrosion as long as the AlN remains intact. An improvement in corrosion resistance due to the formation of an AlN compound layer has been observed [4]. In this paper we report on the feasibility of forming an AlN layer at low energy by a plasma immersion ion implantation (PIII) process onto aluminium samples at incident fluences of $\approx 10^{12}$ atoms $/ \mathrm{cm}^{2}$. The PIII process has been carried out in both pure nitrogen and different argon/nitrogen mixtures.

\section{Experimental}

A $6061 \mathrm{~T} 6$ aluminium rod has been cut in cylindrical pieces, $10 \mathrm{~mm}$ in diameter and with a $5 \mathrm{~mm}$ thickness. All these samples were polished using a sandpaper sequence up to 2000 , then the samples were further polished using solutions of $1,0.3$ and $0.05 \mu \mathrm{m}$ alumina. A chemical polishing was then performed on the samples in order to remove any remaining scratches, using a $1 / 50$ solution of $\mathrm{HCl}$ in methyl alcohol. Then, the pieces were introduced into an SS-304 stainless process chamber with cylindrical geometry, $0.6 \mathrm{~m}$ long and $0.3 \mathrm{~m}$ in diameter, namely, with $\mathrm{a} \approx 42 \mathrm{l}$ capacity. A base pressure of $10^{-6}$ Torr $\left(\approx 10^{-4} \mathrm{~Pa}\right)$ was achieved with a turbomolecular vacuum pump, and then the gas pressure was established at $2 \times 10^{-2}$ Torr $(\approx 2.66 \mathrm{~Pa})$ by admitting the selected implantation gas. Each sample receives a previous $30 \mathrm{~min}$ cleansing stay in argon plasma [5] to be finally implanted during $4.5 \mathrm{~h}$ periods with $70 \% \mathrm{~N} / 30 \% \mathrm{Ar}, 50 \% \mathrm{~N} / 50 \% \mathrm{Ar}$, $70 \% \mathrm{~N} / 30 \% \mathrm{Ar}$ and nitrogen $(99.995 \%$ pure) plasmas. The discharges were produced using a DC power supply at a constant $2000 \mathrm{~mA}$ with an output power of $1200 \mathrm{~W}$. A resulting electron plasma density of about $10^{12} \mathrm{~cm}^{-3}$ was measured with a double cylindrical probe.

The experiments were conducted at a constant sample temperature, in the order of $450^{\circ} \mathrm{C}$, with the bias set at several voltages and pulse widths: $2 \mathrm{kV} / 150 \mu \mathrm{s}$, $3.5 \mathrm{kV} / 75 \mu \mathrm{s}$ and $6 \mathrm{kV} / 50 \mu \mathrm{s}$. In the first two cases the fluence reaches $\approx 10^{12}$ atoms $/ \mathrm{cm}^{2}$ while $\approx 10^{11}$ atoms $/ \mathrm{cm}^{2}$ are recorded in the third one. With an aim at evaluating the efficiency of the PIII process in the treatment of aluminium, different techniques of surface analysis were used including: X-ray diffractometry (XRD), the Raman spectroscopy, the Vickers microhardness tests and profilometry. 


\section{Results and discussion}

\subsection{XRD analysis}

The nitrided compounds formed in the implanted layer were determined by XRD analysis operated by a Siemens D5000 ${ }^{\circledR}$ diffractometer. Figure 1 displays the diffractogrammes from the samples treated in a $70 \% \mathrm{~N} / 30 \% \mathrm{Ar}$ mixture, the peaks were identified using the JCPDS-ICDD X-ray database. It is evident, from the diffraction patterns obtained by glancing angle XRD, the precipitation of nitrides with an hcp structure irrespective of the bias potential, pulse width or gas flux. Likewise, the presence of $\mathrm{Al}_{2} \mathrm{O}_{3}$ (4-0787 JCPDS) is hinted by peaks that can be attributed to the sudden oxidation of the samples when taken out of the implantation chamber. A similar pattern is seen in Figs. 2 and 3. It should be pointed out that the maximal content of AlN in its cubic and hexagonal phases is found in the pure nitrogen case (not shown).

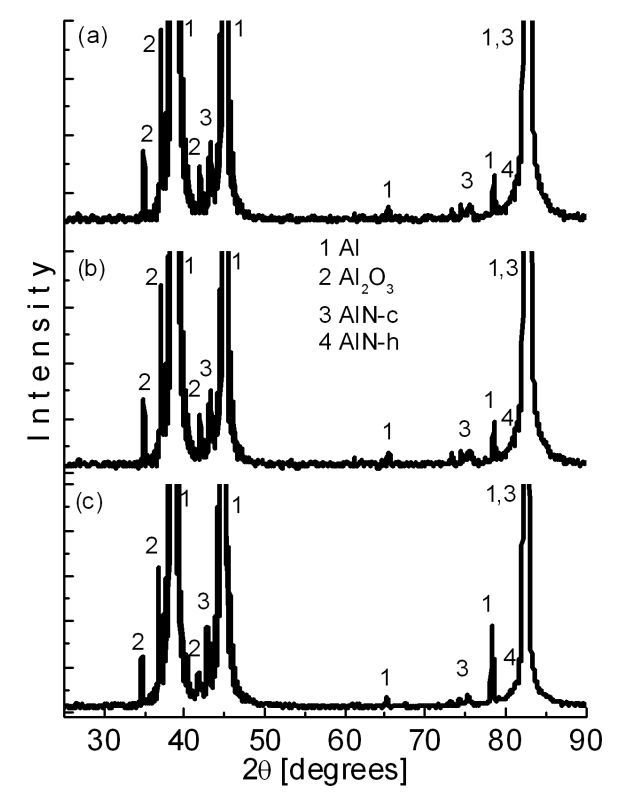

Fig. 1. Diffractogrammes from samples treated in a $70 \% \mathrm{~N} / 30 \% \mathrm{Ar}$ mixture at (a) $2 \mathrm{kV} / 150 \mu \mathrm{s}$, (b) $3.5 \mathrm{kV} / 75 \mu \mathrm{s}$ and (c) $6 \mathrm{kV} / 50 \mu \mathrm{s}$.

Samples treated in a $50 \% \mathrm{~N} / 50 \%$ Ar mixture are shown in Fig. 2. The formation of aluminium nitrides in hexagonal phase appears inhibited. Furthermore, all nitride precipitation either in hexagonal or cubic phases is extinguished, although $\mathrm{Al}_{2} \mathrm{O}_{3}$ remains detectable, as the applied potential reaches $6 \mathrm{kV}$ at a $50 \mu$ s pulse width. Finally, none of the AlN phases is detectable (Fig. 3) in the samples treated in $30 \% \mathrm{~N} / 70 \% \mathrm{Ar}$, with the possible exception of those of $\mathrm{Al}_{2} \mathrm{O}_{3}$. Thus, an increasing deformation of the samples could be inferred from equally increasing Ar concentrations while greater N concentrations would lead to more AlN abundance. The decline in nitride formation as the proportion of Ar in the mixture

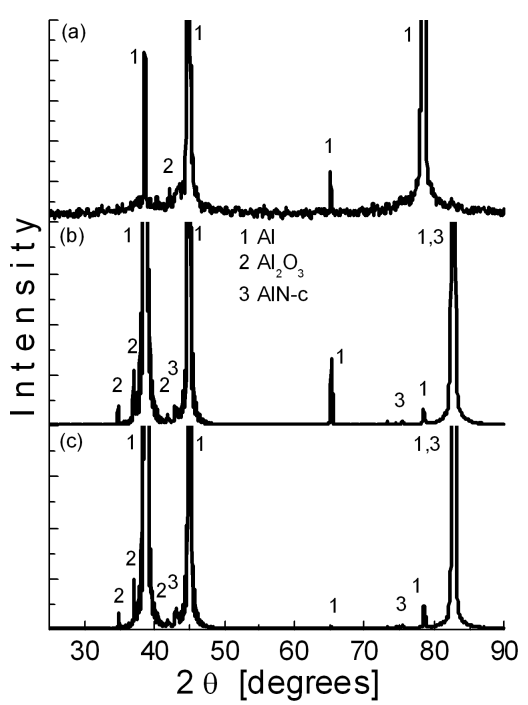

Fig. 2. Diffractogrammes from samples treated in a $50 \% \mathrm{~N} / 50 \% \mathrm{Ar}$ mixture at (a) $6 \mathrm{kV} / 50 \mu \mathrm{s}$, (b) $3.5 \mathrm{kV} / 75 \mu \mathrm{s}$ and (c) $2 \mathrm{kV} / 150 \mu \mathrm{s}$.

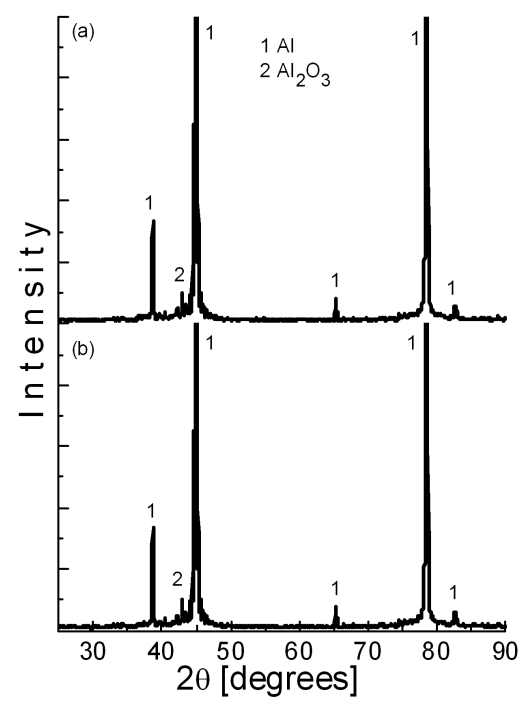

Fig. 3. Diffractogrammes from samples treated in a $30 \% \mathrm{~N} / 70 \% \mathrm{Ar}$ mixture at (a) $3.5 \mathrm{kV} / 75 \mu \mathrm{s}$ and (b) $2 \mathrm{kV} / 150 \mu \mathrm{s}$.

is increased can be attributed to an enhancement of the sputtering due to the argon. In general terms, oxygen was incorporated to the treated samples in the form of $\mathrm{Al}_{2} \mathrm{O}_{3}$, which seems to constitute a not uncommon experimental inconvenience, e.g. [6].

\subsection{Raman analysis}

The samples treated with a mixture of nitrogen-argon were analyzed by means of the Raman spectroscopy (He-Ne laser with $632.8 \mathrm{~nm}$ in wavelength), in order to corroborate the results obtained from XRD. Figure 4 shows the resulting Raman spectra for AlN. The 
$514 \mathrm{~cm}^{-1}$ peak, typical of AlN, is always visible which coincides with the information provided in Figs. 1, 2b and 2c. Likewise, Figs. 2a and 3 confirm the spectra displayed in Fig. 4a, where the absence of aluminium nitride is evident. Our results of XRD and Raman spectroscopy show that the improvement depends on the amount of $\mathrm{N}$ in the $\mathrm{Ar} / \mathrm{N}$ mixture concentration.

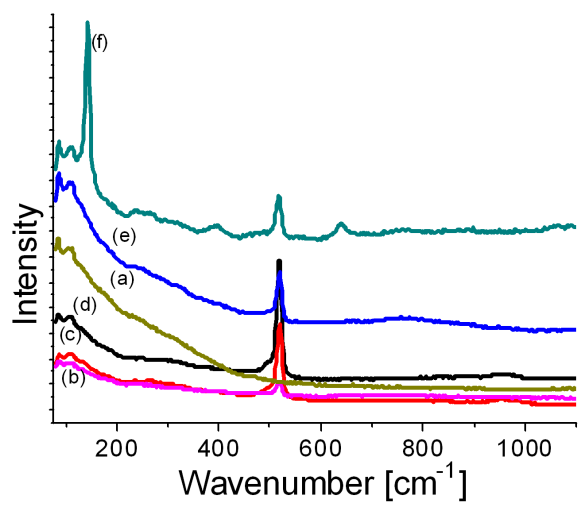

Fig. 4. Raman spectra (a) $30 \% \mathrm{~N} / 70 \%$ Ar mixture, $(b)$ and (c) $50 \% \mathrm{~N} / 50 \% \mathrm{Ar}$ mixture when $6 \mathrm{kV} / 50 \mu \mathrm{s}$ and $2 \mathrm{kV} / 150 \mu \mathrm{s}$, respectively, are applied in the sample, $(d)$, (e), $(f) 70 \% \mathrm{~N} / 30 \%$ Ar mixture with the conditions are $3.5 \mathrm{kV} / 75 \mu \mathrm{s}, 6 \mathrm{kV} / 50 \mu \mathrm{s}$ and $2 \mathrm{kV} / 150 \mu \mathrm{s}$, respectively.

\subsection{Vickers microhardness testing}

The surface hardness was measured with a Buehler ${ }^{\mathrm{TM}}$ Micromet 5104 testing facility (Fig. 5). The substrates

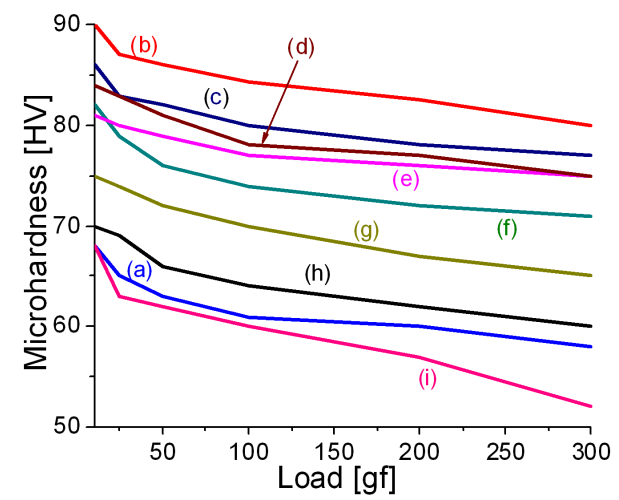

Fig. 5. Microhardness of samples: (a) untreated, (b) pure nitrogen, (c) $50 \% \mathrm{~N} / 50 \% \operatorname{Ar}(2 \mathrm{kV} / 150 \mu \mathrm{s})$, (d) $50 \% \mathrm{~N} / 50 \% \mathrm{Ar}(3.5 \mathrm{kV} / 75 \mu \mathrm{s})$, (e) $50 \% \mathrm{~N} / 50 \% \mathrm{Ar}$ $(6 \mathrm{kV} / 50 \mu \mathrm{s}), \quad(f) \quad 70 \% \mathrm{~N} / 30 \% \mathrm{Ar} \quad(2 \mathrm{kV} / 150 \mu \mathrm{s})$, (g) $70 \% \mathrm{~N} / 30 \% \mathrm{Ar}(3.5 \mathrm{kV} / 75 \mu \mathrm{s})$, (h) $70 \% \mathrm{~N} / 30 \% \mathrm{Ar}$ $(6 \mathrm{kV} / 50 \mu \mathrm{s})$, (i) $30 \% \mathrm{~N} / 70 \% \operatorname{Ar}(2 \mathrm{kV} / 150 \mu \mathrm{s})$.

were gauged using $10 \mathrm{~g}$ to $300 \mathrm{~g}$ loads in $15 \mathrm{~s}$ periods. The hardness of samples treated with the $30 \% \mathrm{~N} / 70 \% \mathrm{Ar}$ mixture diminishes, irrespective of the bias and the pulse width (Fig. 5i), below the value of the untreated control samples considered in Fig. 5a which could be understood as a symptom of thermal softening. In all other cases the microhardness increased along with the nitride formation. In particular, the highest microhardness values were attained in pure nitrogen.

\subsection{Roughness test}

A Mitutoyo Surftest 402 profilometer has been applied to the mean roughness $(\mathrm{Ra})$ of the treated samples: a parameter particularly relevant as it is closely related with the friction coefficient affecting the overall dynamic response of the material surface [7]. Maximal roughness values are found in samples treated in the $50 \% \mathrm{~N} / 50 \% \mathrm{Ar}$ mixture, irrespective of the bias and the pulse width; albeit a general roughness increase with respect to the untreated case is observed (Fig. 6).

\section{Conclusions}

The PIII treatment of 6061 T6 aluminium samples results in the surface formation of nitrides when plasmas made out of mixtures of argon and, at least, $50 \%$ nitrogen are applied and when sample temperatures are around $450{ }^{\circ} \mathrm{C}$. The presence of $\mathrm{cp}$ and hcp AlN has been detected by X-ray diffraction where the peak intensities increase along with the nitrogen content. Likewise, the presence of the hexagonal phase (HP) has been detected when either pure nitrogen or a $50 \%$ mixture have been used, showing a correlation between the h phase and the microhardness. Also, the signature peak of AlN has been confirmed by the Raman spectroscopy. Both XRD and Raman spectroscopy results show that the surface improvement is enhanced with the $\mathrm{N}$ proportion in the $\mathrm{Ar} / \mathrm{N}$ mixture concentration.

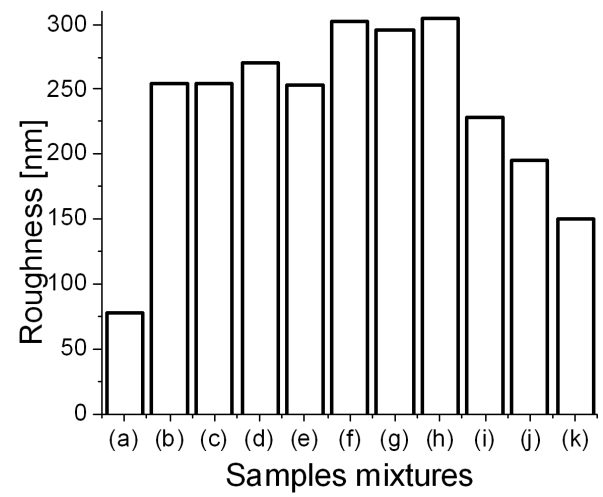

Fig. 6. Roughness of: (a) untreated sample, $(b)$ pure nitrogen, (c) $70 \% \mathrm{~N} / 30 \% \mathrm{Ar}(2 \mathrm{kV} / 150 \mu \mathrm{s}),(d) 70 \% \mathrm{~N} /$ $30 \% \operatorname{Ar}(3.5 \mathrm{kV} / 75 \mu \mathrm{s})$, (e) $70 \% \mathrm{~N} / 30 \% \operatorname{Ar}(6 \mathrm{kV} / 50 \mu \mathrm{s})$, (f) $50 \% \mathrm{~N} / 50 \% \operatorname{Ar}(2 \mathrm{kV} / 150 \mu \mathrm{s}),(g) 50 \% \mathrm{~N} / 50 \% \mathrm{Ar}$ $(3.5 \mathrm{kV} / 75 \mu \mathrm{s}), \quad(h) \quad 50 \% \mathrm{~N} / 50 \% \operatorname{Ar}(6 \quad \mathrm{kV} / 50 \mu \mathrm{s})$, (i) $30 \% \mathrm{~N} / 70 \% \mathrm{Ar} \quad(2 \mathrm{kV} / 150 \mu \mathrm{s}), \quad(j) 30 \% \mathrm{~N} / 70 \% \mathrm{Ar}$ $(3.5 \mathrm{kV} / 75 \mu \mathrm{s}),(k) 30 \% \mathrm{~N} / 70 \% \operatorname{Ar}(6 \mathrm{kV} / 50 \mu \mathrm{s})$.

The maximal microhardness values were found in samples treated with the equal part mixture and biased between $2 \mathrm{kV}$ and $6 \mathrm{kV}$. The maximal roughness was 
achieved with this gas mixture in all cases, although increasing along with the implantation pulse width up to a $300 \mathrm{~nm}$ peak at $150 \mu \mathrm{s}$. The latter critical value remains invariant under the pure nitrogen plasma, at longer $4.5 \mathrm{~h}$ implantation periods. A compromise between high hardness and low roughness in pure nitrogen is observed due to a competition between sputtering and nitriding after, at least, $3.5 \mathrm{~h}$ of treatment.

\section{Acknowledgments}

This work has received financial support from CONACYT and DGEST, Mexico. The authors highly appreciate the technical collaboration received from M.T. Torres M., I. Contreras V., and P. Angeles E.

\section{References}

[1] D. Manova, M. Schreck, S. Mändl, B. Stritzker, B. Rauschenbach, Surf. Coat. Technol. 151-152, 72 (2002).
[2] M.M.M. Bilek, D.R. McKenzie, R.N. Tarrant, T.W.H. Oates, P. Ruch, K. Newton-McGee, Yang Shi, D. Tompsett, H.C. Nguyen, B.K. Gan, D.T. Kwok, Contrib. Plasma Phys. 44/5-6, 465 (2004).

[3] I.E. Saklakoğlu, J. Mater. Proc. Technol. 209-4, 1796 (2009).

[4] E. Richter, U.R. Günzel, S. Parasacandola, T. Telbizova, O. Kruse, W. Möller, Surf. Coat. Technol. 128-129, 21 (2000).

[5] B.K. Gan, M.M.M. Bilek, D.R. McKenzie, Yang Shi, D.A. Tompsett, M.B. Taylor, D.G. McCulloch, J. Phys., Condens. Matter 16, 1751 (2004).

[6] C. Blawert, B.L. Mordike, Nucl. Instrum. Methods Phys. Res. B 127/128, 873 (1997).

[7] O. Wouters, W.P. Vellinga, R. van Tijum, J.Th.M. de Hosson, Acta Mater. 54-10, 2813 (2006). 